Article

\title{
Superior Mechanical Behavior and Fretting Wear Resistance of 3D-Printed Inconel 625 Superalloy
}

\author{
Yong Gao ${ }^{1}$ and Mingzhuo Zhou ${ }^{2, *}$ \\ 1 Wuhan Institute of Marine Electric Propulsion, Wuhan 430064, China; 18907120357@163.com \\ 2 The State Key Laboratory of Digital Manufacturing Equipment and Technology, School of Mechanical \\ Science and Engineering, Huazhong University of Science and Technology (HUST), Wuhan 430074, China \\ * Correspondence: mingzhuo@hust.edu.cn; Tel.: +86-132-6067-8851
}

Received: 17 October 2018; Accepted: 16 November 2018; Published: 1 December 2018

check for updates

\begin{abstract}
Additive manufacturing (AM) nickel-based superalloys have been demonstrated to equate or exceed mechanical properties of cast and wrought counterparts but their tribological potentials have not been fully realized. This study investigates fretting wear behaviors of Inconel 625 against the $42 \mathrm{CrMo}_{4}$ stainless steel under flat-on-flat contacts. Inconel 625 is prepared by additive manufacturing (AM) using the electron beam selective melting. Results show that it has a high hardness (335 HV), superior tensile strength $(952 \mathrm{MPa})$ and yield strength $(793 \mathrm{MPa})$. Tribological tests indicate that the AM-Inconel 625 can suppress wear of the surface within a depth of only $\sim 2.4 \mu \mathrm{m}$ at a contact load of $106 \mathrm{~N}$ after $2 \times 104$ cycles. The excellent wear resistance is attributed to the improved strength and the formation of continuous tribo-layers containing a mixture of $\mathrm{Fe}_{2} \mathrm{O}_{3}, \mathrm{Fe}_{3} \mathrm{O}_{4}, \mathrm{Cr}_{2} \mathrm{O}_{3}$ and $\mathrm{Mn}_{2} \mathrm{O}_{3}$.
\end{abstract}

Keywords: nickel; fretting; hardness; wear mechanisms

\section{Introduction}

Since the first 3D printing process appeared in the Japanese edition of the IEICE Transactions on Electronics in 1981, explorations on different metal components from metallic powders have rapidly increased worldwide for investigating high-performance metallic materials or complex structures in the fundamental scientific research. It is noteworthy that the additive manufacturing (AM) is becoming the focus of intensive research owing to its advantages of completely melting the powders and producing fully dense microstructures during the fabrication without pretreatment, thus making them a superior technique in AM processes. In addition to the ability of AM to create complex structures with a high density, the capability to prepare materials with an ultra-high tensile strength (TS) and a superior yield strength (YS) has also been demonstrated. The excellent TS reported for AM-processed steel, titanium and nickel-based alloy are 1470 [1], 1510 [2] and $1184 \mathrm{MPa}$ [3], respectively, with corresponding YS of 1100, 1440 and $933 \mathrm{MPa}$.

As one of the most important nickel-based alloys, Inconel 625 has shown exceptional properties such as strong resistance to corrosion, high tensile strength and yield strength, as well as high resistance to chloride-ion stress-corrosion cracking [4,5] and thus has been widely applied in advanced areas including sea-water applications. It has been used as propeller blades for motor patrol gunboats, submarine auxiliary propulsion motors and submarine quick-disconnect fittings [4]. Potential applications are springs, seals, fasteners and oceanographic instrument components. Conventionally, Inconel 625 alloys are hard-to-cut materials during machining, which normally require high cutting temperatures due to the low thermal conductivity and volume-specific heat. Compared with traditional casting and forging parts, Inconel 625 obtained by the AM process shows much higher tensile strength [6,7] and has hardness as high as $343 \mathrm{HV}$ with primary dendrite arm space of $\sim 0.5 \mu \mathrm{m}$ due to the rapid cooling speed $(106 \mathrm{~K} / \mathrm{s})$ [6]. These unique properties make AM processes very 
attractive for designing the high-strength and durable Inconel 625 applied in aerospace, automotive and robotics.

However, Inconel 625 superalloy applied in moving assemblies normally subjects to various critical conditions such as cyclic fatigue loading, corrosion and thermal stresses and thus suffers from serious mechanical energy dissipation caused by friction and wear. Accordingly, a fine control of friction and wear for Inconel 625 superalloy is desirable for improving the reliability of moving mechanical systems and is also an attractive fundamental scientific research.

Iwabuchi [8] first investigated fretting properties of Inconel 625 under different pressures at elevated temperature and high vacuum. The friction coefficient with a high value of 1.7 at pressures below $0.1 \mathrm{~Pa}$ was observed and it decreased to a low value of 0.55 at $105 \mathrm{~Pa}$. In order to enhance the wear resistance, the reinforced Inconel 625 with considerably size-reduced TiC particles was successfully prepared by Hong et al. [9] using the laser metal deposition (LMD). During the LMD process, the in-situ interfacial reaction could be tailored between the TiC reinforcement and the Ni-based metal matrix to improve the interfacial wettability and bonding coherence and thus greatly enhancing the wear resistance. Recently, an accurate 3D finite element model was developed by Lotfi et al. [10] to predict the wear of Inconel 625 superalloy, acting as tools with complex geometries, with PVD-TiAlN coated carbide and ceramic inserts. It was found that the low-cutting speed, low-depth cut and the middle-level feed rate would be appropriate for Inconel 625 with PVD-TiAlN coated carbide insert, while ceramic insert demonstrated better performance under the condition of a high-cutting speed.

Recently, increasing attentions on AM metallic materials have been received for designing components with a high complexity. However, data of tribological performance of Inconel 625 superalloy fabricated by AM are very limited. It has been demonstrated that alloys prepared by AM showed higher mechanical properties surpassing their traditional wrought or cast counterparts [11-15]. Herein, Inconel 625 superalloy is prepared in this work by electron beam selective melting (EBSM). Mechanical and tribological behaviors are systemically investigated via an AG-Xplus $100 \mathrm{kN}$ mechanical test system and a flat-on-flat tribo-system, respectively.

\section{Experiments}

\subsection{Material Preparation}

The initial powders selected for this study were commercial Inconel 625 produced by gas atomization with the particle sizes ranging from 22 to $47 \mu \mathrm{m}$ (as shown in Figure 1) and used without further processing. The data were collected based on the standard method in Reference [16]. The powder is composed of Ni-Cr-Fe-Nb-Mn-Mo-Si. The chemical compositions are given in Table 1. In the present study, Inconel 625 samples were fabricated on a $250 \times 250 \mathrm{~mm}$ building platform by EBSM R2 device with the beam power of $300 \mathrm{~W}$ and scan speeds of $500 \mathrm{~mm} / \mathrm{s}$. The processing values were demonstrated as the optimum parameters for manufacturing AM-nickel based super alloys with almost fully density. Figure 2 represents an overview of the AM processing strategy. Each layer was scanned once using vectors oriented along either the $X$-axis (scan direction- $\mathrm{x}, \mathrm{SD}_{\mathrm{x}}$ ) or the $Y$-axis (scan direction-y, $\mathrm{SD}_{\mathrm{y}}$ ), alternatively. The fabricated parts were wire-cut from the steel substrate for mechanical polishing with emery papers down to 1200 grit and $0.5 \mu \mathrm{m}$ wet diamond pastes.

Table 1. Chemical compositions of the initial powders.

\begin{tabular}{lccccccc}
\hline & \multicolumn{7}{c}{ Chemical Composition (wt. \%) } \\
\hline \multirow{2}{*}{ Elements Mass Ratio } & $\mathrm{Ni}$ & $\mathrm{Cr}$ & $\mathrm{Fe}$ & $\mathrm{Nb}$ & $\mathrm{Mo}$ & $\mathrm{Mn}$ & $\mathrm{Si}$ \\
& $\mathrm{Bal}$. & 20.5 & 3.4 & 3.6 & 8.9 & 0.4 & 0.5 \\
\hline
\end{tabular}




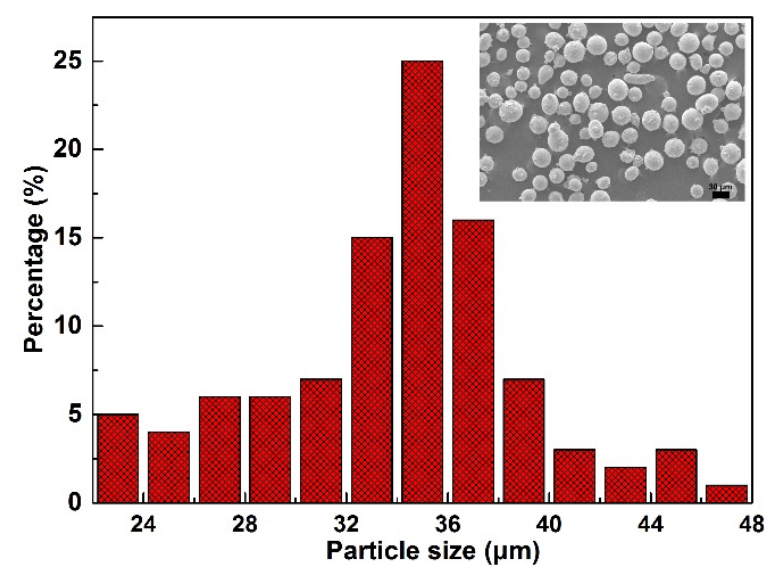

Figure 1. Size distribution of initial particles fabricated by the gas atomization.
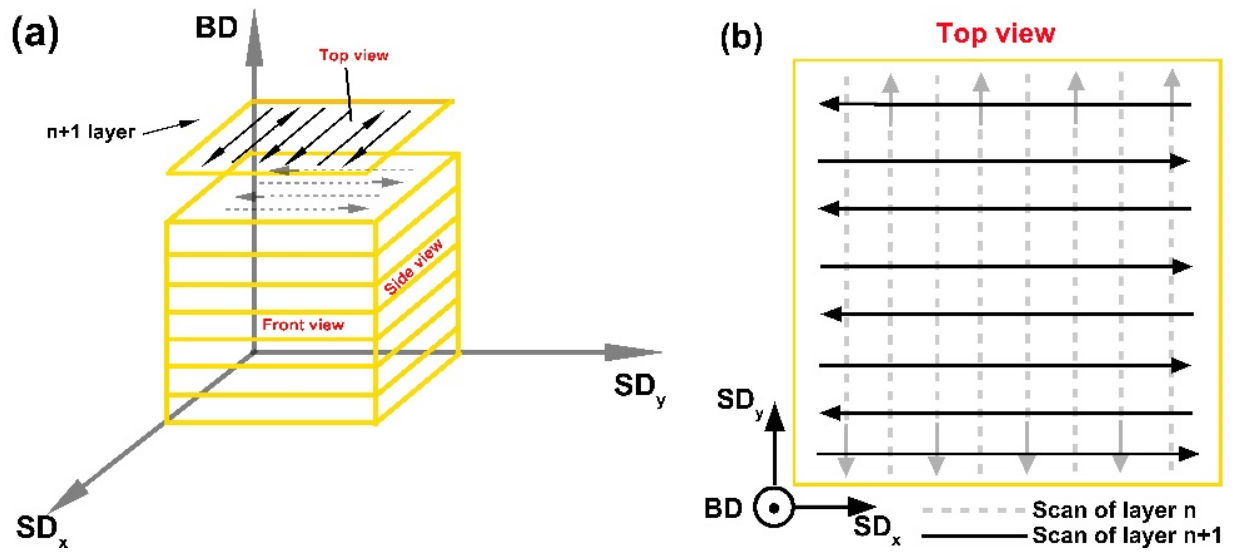

Figure 2. Overview of the AM processing strategy. The build (BD) and scan directions $\left(\mathrm{SD}_{\mathrm{x}}\right.$ and $\left.\mathrm{SD}_{\mathrm{y}}\right)$ are indicated with respect to the sample coordinates: (a) the different views of the sample; (b) top view of the sample with the bidirectional scan vectors.

\subsection{Mechanical and Tribological Tests}

The Vicker's hardness of AM-processed specimens was measured using a HVS-1000 Vicker's hardness instrument with a load of $1 \mathrm{~kg}$ and a dwell time of $10 \mathrm{~s}$. Five random positions for hardness testing are selected on the surfaces of samples and the mean value was obtained. The density was determined based on the Archimedes principle. Uniaxial tension specimens were extracted from the AM materials by wire electro discharge machining with a gauge dimension of $5.3 \mathrm{~mm}$ (length) $\times$ $2.9 \mathrm{~mm}$ (width) $\times 1.8 \mathrm{~mm}$ (thickness) on this basis of methods in Reference [17]. Samples were clamped by the ends of the plate-type samples. Mechanical properties were assessed by rate-controlled tensile tests at nominal strain rates of $1 \times 10^{-3} \mathrm{~s}^{-1}$ using a Shimadzu AG-100 $\mathrm{kN}$ equipment. All tensile tests were repeated five times.

To evaluate the fretting wear resistance of AM-prepared Inconel 625 alloys, the wear tests were carried out using a fretting test system with a flat-on-flat configuration at contact loads of 40-106 N and a frequency of $2 \mathrm{~Hz}$ for 20,000 cycles. Wear test specimens were extracted from the fabricated parts by wire electro discharge machining with a dimension of $30 \mathrm{~mm}$ (length) $\times 30 \mathrm{~mm}$ (width) $\times$ $7 \mathrm{~mm}$ (thickness). Details about wear test configuration can be found in our previous works [18-21]. The experimental parameters were set based on the practical operating conditions of the blade bearing [16]. The contact area of the fretting surface was $6.75 \mathrm{~mm}^{2}$. The angular displacement amplitude $(\theta)$ of the fretting test was $1.5^{\circ}$. The $42 \mathrm{CrMo} 4$ stainless steel with a hardness of $25 \mathrm{HRC}$ and a roughness of $R_{a}=0.2 \mu \mathrm{m}$ which is generally used for blade bearing in a propeller was used as a mating material. Tribological experiments were performed at a relative humidity of about $60 \%$. The wear volume was determined by a 3D digital microscope. All the tests were carried out at the 
same condition for three times to make sure the repeatability of the experimental results at the same conditions and the average results were recorded.

\subsection{Microstructural Characterization}

The crystalline size and phase composition of the initial powders and sintered samples were determined by X-ray diffraction (XRD, Shimadzu Corp., Tokyo, Japan) on a XRD-7000S X-ray diffractometer with $\mathrm{Cu} \mathrm{K} \alpha$ radiation. A JSM 7600F field-emission scanning electron microscope (FE-SEM, JEOL Ltd., Tokyo, Japan) is used to examine and analyze the microstructures of the wear scars after the friction and wear tests and the fractography after tensile tests with an acceleration voltage of $5 \mathrm{kV}$ and current of $7 \mu \mathrm{A}$. The morphologies of the wear scars were also investigated by the 3D optical microscope (OM, Olympus, Tokyo, Japan). The composition of the wear tracks was analyzed by a VG Multilab 2000 X-ray photoelectron spectroscope (XPS, Thermo VG Scientific, Leicestershire, UK).

\section{Results and Discussion}

Metal AM process typically exhibits complex transient material consolidation processes that have an important effect on the resulting grain size and crystal texture $[13,14]$ and thereafter influence mechanical and tribological behaviors of the materials including strength, hardness, friction and wear properties.

\subsection{Micro-Hardness and Relative Density}

Table 2 gives the micro-hardness and relative density of the as-prepared specimen and other Inconel 625 alloys fabricated by different methods such as sintering and welding. Densification result of AM-samples analyzed by the Archimedes principle shows that the relative density of Inconel 625 prepared by AM reaches a value of $99.7 \%$, indicating the printed part from micro-cracks and micro-voids which can promote the increase of the mechanical and tribological performance of materials. Micro-hardness result of AM-samples shows the improved hardness compared to that of the sintering-processed and welding-processed samples. The improvement of the hardness can be ascribed to the residual stresses in AM parts introduced by layer-by-layer fabricating process. For the case of a sufficiently high densification without the formation of micro-cracks or micro-pores, the retention of a reasonable level of residual stress in AM-processed parts favors the enhancement of hardness [15].

Table 2. Micro-hardness and relative density of the as-prepared specimen and other Inconel 625 alloys fabricated by different methods.

\begin{tabular}{ccccc}
\hline Specimen & Method & $\begin{array}{c}\text { Micro-Hardness } \\
\text { (HV) }\end{array}$ & $\begin{array}{c}\text { Relative } \\
\text { Density }\end{array}$ & Ref. \\
\hline As-prepared & AM & 335 & $99.7 \%$ & Present work \\
Inconel 625 & Sintering + ageing & 327 & $99.2 \%$ & {$[16]$} \\
Inconel 625 & AM & 343 & - & {$[7]$} \\
Inconel 625 & Gas tungsten arc deposition & 328 & - & {$[17]$} \\
Inconel 625 & Gas tungsten arc welding & 270 & - & {$[18]$} \\
Inconel 625 & Sintering & 275 & 91.8 & {$[19]$} \\
Milled Inconel 625 & Sintering & 320 & 84 & {$[19]$} \\
Inconel 625 & Welding & 252 & - & {$[20]$} \\
\hline
\end{tabular}

\section{2. $X R D$ Analyses}

The XRD results of the as-received initial Inconel 625 powders and specimens after AM process are shown in the Figure 3. It can be seen that the AM-sample mainly consists of Ni-base austenite phase ( $\gamma$ phase) with crystal size of $\sim 5.61 \mu \mathrm{m}$. Lattice parameter of the as-received powders is $3.5899 \AA$ and decreases after AM process to $3.5716 \AA$, which can be demonstrated by a right peak shift on the $2 \theta$ 
scale for the AM-Inconel 625 (the inset in the Figure 3). Peak shifts are usually caused by the change of the crystal lattice whereas shifts to higher angles are caused by compression of the crystal lattice. This decrease can be attributed to the depletion of $\mathrm{Nb}, \mathrm{Cr}$ and Mo in the $\gamma$-matrix, since these elements participate in the formation of intermetallic phases [22]. Additionally, a lattice parameter shift in the AM sample compared to the standard alloys $625 \mathrm{fcc} \gamma$-Ni phase also indicates that potentially precipitates in the $\gamma$-Ni matrix are formed during the AM process. However, the phases precipitated in $\gamma$-Ni matrix are not detected by XRD due to a relatively low volume fraction of these precipitates. The result is similar to the previous studies [23]. Only three peaks including $111_{\gamma}, 200_{\gamma}$ and $220_{\gamma}$ are detected and this reveals the pattern of the columnar dendritic growth [24].

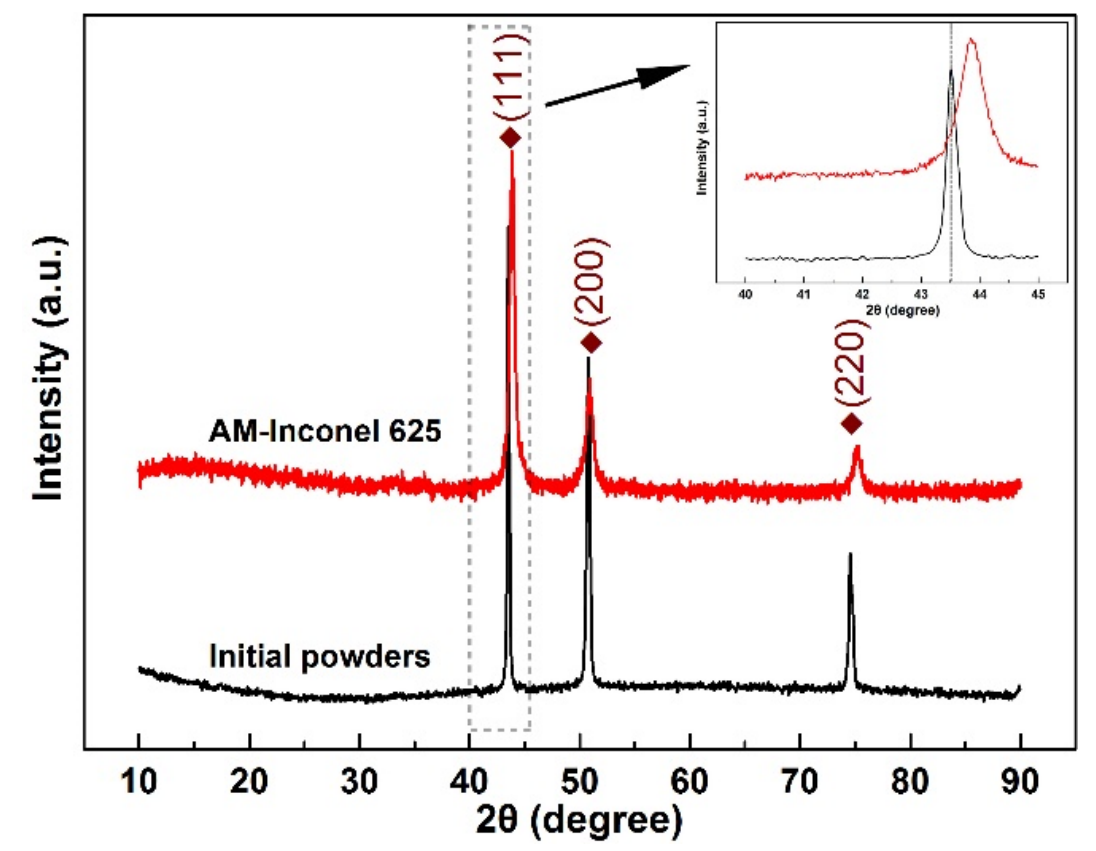

Figure 3. XRD results of the as-received initial Inconel 625 powders and specimen after AM process.

\subsection{Tensile Tests}

Figure 4a shows one of the five performed tensile stress-strain curves of Inconel 625 alloy. The inset gives comparison results of the tensile test for Inconel 625 samples in the present work and literatures [25-31]. Apparently, the tensile strength of different processing samples are not identical. Compared with the available data of sintering-processed and welding-processed samples, the ultimate TS of AM-processed Inconel 625 is significantly improved. The sintering and welding samples have a lower ultimate TS (420-830 MPa) compared to that of AM-processed specimens (810-1070 MPa). In this work, Inconel 625 sample prepared by AM have a relatively high ultimate TS of $952 \pm 18 \mathrm{MPa}$.

Previous work shows that in general, components made by AM have higher yield and tensile strengths than those of wrought materials of the alloy [32]. The yield strength in equiaxed metals normally relates to the grain size followed by the Hall-Petch low, which can be described as

$$
\sigma_{y}=\sigma_{o}+\frac{\kappa}{\sqrt{d}}
$$

where $\sigma_{y}$ is the yield strength, $d$ is the grain size and $\sigma_{0}$ and $k$ are material constants. To link the yield strength to the grain size of Inconel 625 alloys, yield strength results extracted both from this work and literatures are plotted versus $d^{-0.5}$, as shown in Figure $4 \mathrm{~b}$. A linear fit of the yield strength versus relevant grain size gives values of $\sigma_{0}=105 \mathrm{MPa}$ and $k=1380 \mathrm{MPa} \sqrt{\mu \mathrm{m}}$ to describe the Hall-Petch relationship between the yield strength and the grain size of Inconel 625. Nevertheless, there are some discrepancies in the predicted yield strength versus $d^{-0.5}$, in which the datum in the present 
work (793 MPa) does not lie on the line. The value of the yield strength is relative higher than the predicted result, which is likely due to the formation of precipitates in the AM process (Figure 3). Further analysis regarding the precipitate strengthening of the AM-Inconel 625 specimen needs to be carried out after the tensile tests.
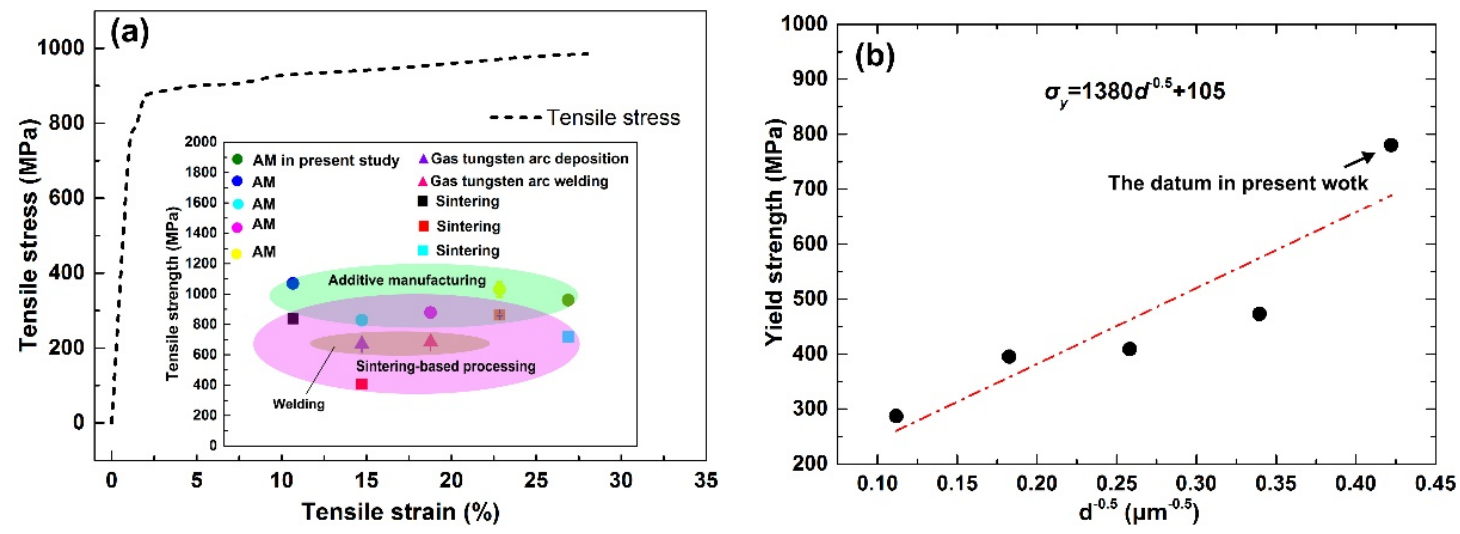

Figure 4. (a) Tensile stress-strain curve of Inconel 625 alloy and (b) yield strengths plotted versus $d^{-0.5}$ for Inconel 625 samples in the present work and literatures, the inset shows the comparison results of tensile strength for Inconel 625 samples in the present work and literatures.

The corresponding fractography of AM-Inconel 625 tested at room temperature is shown in Figure 5. Dimples and particle facets of precipitates are clearly found in the fracture surface, while no obviously microcrack can be observed. This suggests that the failure of AM-Inconel 625 shows a ductile character. A high magnification of the fracture surface (Figure $5 b$ ) shows spherical precipitates with a size around $600 \mathrm{~nm}$. In the case of precipitate strengthening $\left(\Delta \sigma_{p}\right)$, the dislocation shearing or the Orowan dislocation bypass is believed to be the main strengthening mechanism. For the shearing mechanism, the improvement of the yield strength can be ascribed to contributions of coherency strengthening $\left(\Delta \sigma_{c s}\right)$, modulus mismatch strengthening $\left(\Delta \sigma_{m s}\right)$ and order strengthening $\left(\Delta \sigma_{o s}\right)$ [33]. The shearing mechanism is more significant for coherent precipitates with small radii and the transition to Orowan bypass mechanism is active when the radii of coherent precipitates reach a critical value or when the precipitate is separate [34], as can be seen in this work (Figure 5b).
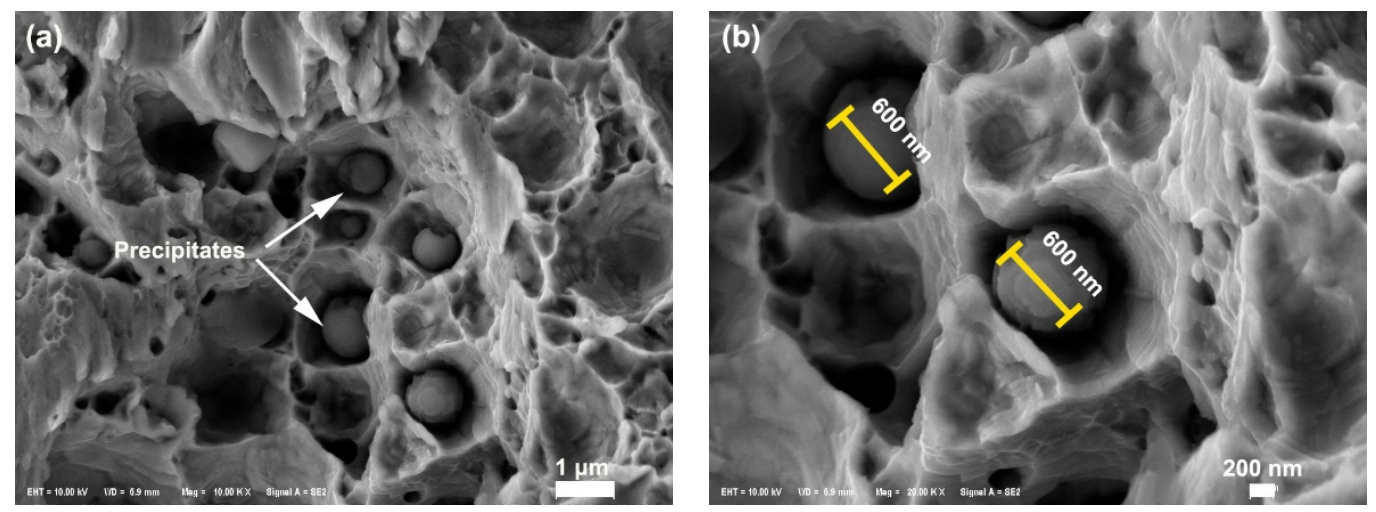

Figure 5. (a) Fractography of AM-Inconel 625 after tensile test at room temperature; (b) High magnification of the fracture surface in (a).

For the Orowan dislocation bypass mechanism, the increase in the yield strength can be expressed as

$$
\Delta \sigma_{o r}=M \frac{0.4 G b}{\pi \lambda} \frac{\ln \left(\frac{2 \bar{r}}{b}\right)}{\sqrt{1-v}}
$$


where $M=3.06$ is the mean orientation factor for the fcc polycrystalline matrix [34]; $G$ is the shear modulus, $81.4 \mathrm{GPa} ; v=0.28$ is Poisson's ratio of the Inconel 625 matrix; $b$ is the magnitude of the Burgers vector, $0.179 \mathrm{~nm}$. For Ni-based superalloys, the dislocations in $\gamma$ phase have a Burgers vector of $a / 2$ since precipitates reside within a coherent face-centered cubic (fcc) matrix [35]; $\bar{r}=\sqrt{2 / 3} r$ is the mean radius of a circular cross section in a random plane for a spherical precipitate, $r$ is the radius of a precipitate, $600 \mathrm{~nm}$. The distribution of spherical precipitates in a cubic grid is applied to simplify a small volume fraction of precipitates, $\lambda$ can be expressed as follows:

$$
\lambda=2 \bar{r}\left(\sqrt{\frac{\pi}{4 f}}-1\right)
$$

where $f$ is the volume fraction of precipitates, $0.8-1.1 \%$. Thus, the strengthening contribution from the precipitates $\Delta \sigma_{p}$ is $27.9 \mathrm{MPa}$.

Since the grain size of the AM-Inconel 625 is significantly reduced, if compared to that of initial powders, the grain boundary (GB) strengthening mechanism is next considered as a possible cause of the YS improvement. It has been established that GB strengthening obeys the Hall-Petch relationship [34]:

$$
\Delta \sigma_{G B}=K^{H P} d^{-1 / 2}
$$

where $K^{H P}$ and $d$ are the Hall-Petch coefficient $\left(0.158 \mathrm{MPa} \mathrm{m}^{1 / 2}\right.$, [36] and the average grain diameter $(5.61 \mu \mathrm{m})$, respectively. The strength increment due to $\mathrm{GB}, \Delta \sigma_{G B}$, is $66.7 \mathrm{MPa}$.

The contributions from different strengthening mechanisms can be added linearly $[37,38]$. Therefore, the yield strength of the AM-Inconel 625 alloy $\sigma_{y}$ can be expressed as:

$$
\sigma_{y}=\sigma_{0}+\Delta \sigma_{G B}+\Delta \sigma_{p}
$$

where $\sigma_{0}$ is $687.6 \mathrm{MPa}$, calculated by the linear relation in Figure $4 \mathrm{~b}$. Using the results from Equation, $\sigma_{y}$ is $782.2 \mathrm{MPa}$, which is in good agreement with the experimental result of the yield strength (793 MPa). It is worth noting that the full density (100\% relative density) is not achieved during the AM process and the presence of a small amount of porosity in the printed samples is not taken into the consideration in strength calculations. Micro-pores may lead to premature failure through the coalescence of micro-pores and the subsequent propagation of cracks, especially for tensile tests.

From the good agreement between the results of the calculation and the experiment, it is reasonable to conclude that the strength of AM-processed Inconel 625 alloys is predictable by quantifying the contributions from different active strengthening mechanisms. The quantification of different strengthening mechanisms can be determined from characterizing the microstructure of Inconel 625 (e.g., distribution and size of spherical precipitates, grain size, etc.), providing a guideline for designing advanced high performance bulk metallic materials by additive manufacturing.

\subsection{Tribological Tests}

Figure 6 shows the relationship between the friction behaviors of AM-Inconel 625 and the number of cycles at a contact load of 106 N. Figure 6 a gives friction torques of the material tested after $2 \times$ $10^{4}$ cycles. The friction torque increases rapidly over the first $5 \times 10^{3}$ cycles and reaches a high value $(\sim 0.55)$. Then the friction torque maintains a relative steady state $(\sim 0.48)$. The friction behaviors of AM-Inconel 625 can be more clearly observed in the Figure $6 \mathrm{~b}$, in which the friction coefficient of the specimen is plotted against fretting cycles. The friction coefficient reaches a peak value of 0.62 at about $5 \times 10^{3}$ cycles and decreases to a low value of $\sim 0.50$ after $7 \times 10^{3}$ cycles. The friction coefficient of AM-processed Inconel 625 is similar to that of the traditional Inconel 625 alloy reported in the previous work [8]. 

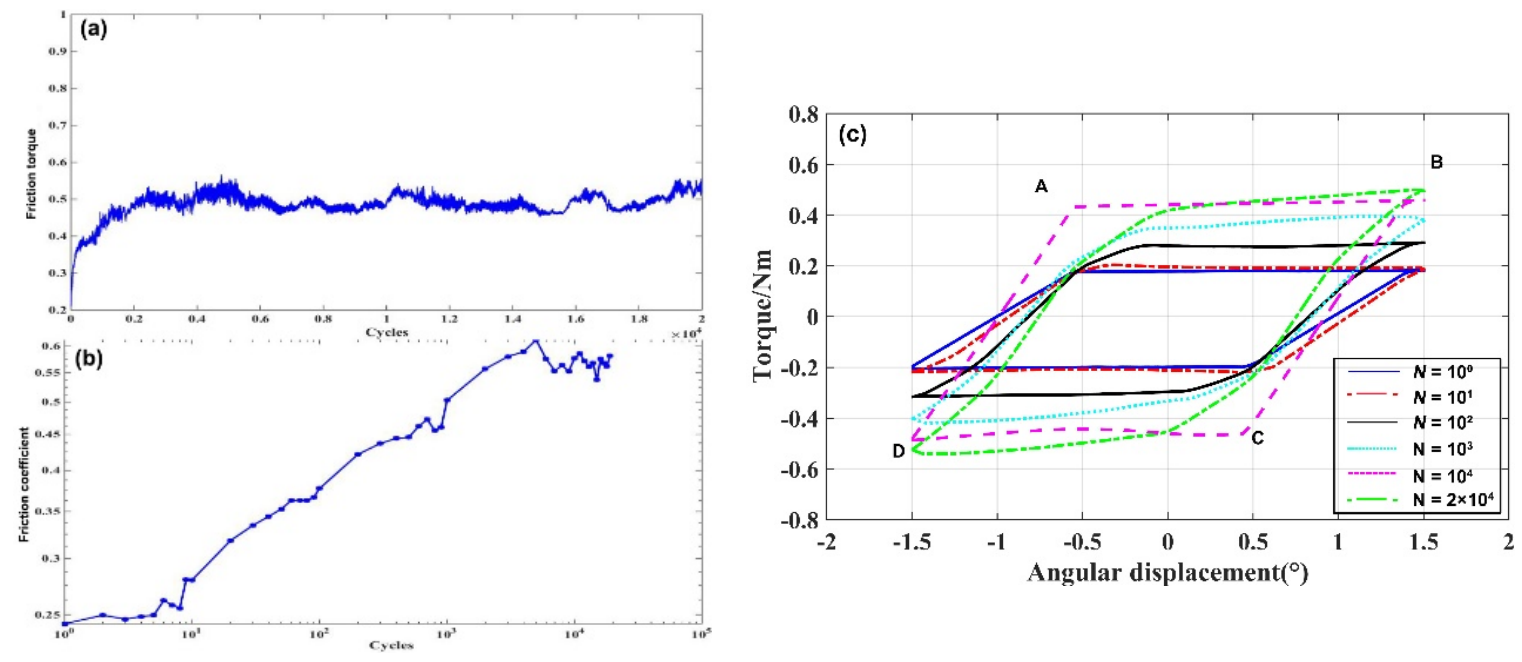

Figure 6. Relationship between the (a) friction torques and (b) friction coefficient of AM-Inconel 625 and the number of cycles at room temperature; (c) typical friction torque versus angular displacement amplitude curves ( $T$ - $\theta$ curves) at the fretting cycles of $10^{0}, 10^{1}, 10^{2}, 10^{3}, 10^{4}$ and $2 \times 10^{4}$.

The typical friction torque versus angular displacement amplitude curves (T- $\theta$ curves) at the fretting cycles of $10^{0}, 10^{1}, 10^{2}, 10^{3}, 10^{4}$ and $2 \times 10^{4}$ are displayed in Figure $6 \mathrm{c}$ to evaluate the fretting running state. For the $T-\theta$ curve with a parallelogram shape, the segments $\overline{\mathrm{AB}}$ and $\overline{\mathrm{CD}}$ correspond to the sliding of the two contact surfaces and the tilt segments $\overline{\mathrm{BC}}$ and $\overline{\mathrm{DA}}$ correspond to the static friction force. All the $T-\theta$ curves show the shape of quasi-parallelograms, undoubtedly indicating the gross slip between the contact interfaces during the fretting wear process. For an individual loop, the tangential force is almost constant and without tips at the end, indicating that adhesion wear is mild between the contact surfaces.

To explore the wear mechanism of AM-processed Inconel 625 alloy, optical images of the fretting wear tracks from tests at 40-106 N loads are shown in Figure 7. Figure 7a represents the measurements obtained from the test of AM-processed Inconel 625 at a contact load of $40 \mathrm{~N}$, showing the material transfer from the counterpart. The optical image of the fretting wear track after test at 62 and $84 \mathrm{~N}$ are shown in Figure $7 \mathrm{~b}, \mathrm{c}$, respectively. Similarly, material transfer can be observed on both wear tracks and apparent surface oxidation occurred at a contact load of $84 \mathrm{~N}$. It has been confirmed that fretting wear decreased substantially for most friction couples (metals) as the relative humidity increases from zero to fifty percent [39]. In this study, with humidity about $60 \%$, moisture promotes the formation of soft iron hydrates such as abrasive $\mathrm{Fe}_{3} \mathrm{O}_{4}$, magnetite and a magnetic oxide of iron. Figure $7 \mathrm{~d}$ shows the wear track obtained after test at a contact load of $106 \mathrm{~N}$. Severe oxidation on the surface could be observed. All the tests at different contact loads last for $2 \times 10^{4}$ cycles without experiencing a significant amount of surface damage, indicating superior wear-resistance of AM-processed Inconel 625.

Fretting wear is quantified according to a change in wear volume of the fretting wear track, as shown in Figure 8a. All the wear volume tests were carried out at the same condition for three times, yielding standard error bars. The 3D optical microscope is used to measure the wear volume and depth after fretting tests. For testing at $40-86 \mathrm{~N}$, a slight increase in wear volume proves the mild wear in the wear surfaces. Since increment of wear volume is relative pronounced at the highest load of $106 \mathrm{~N}$, the wear still remains slight. The critical load, at which the transition from mild to severe wear occurs, is primarily a material property [40-55]. The propagation of cracks which can result in the significant wear becomes more difficult as the fracture toughness of the material increases. Therefore, it can be inferred that the AM-Inconel 625 would show a high fracture toughness, leading to the superior wear-resistance at varying load condition. 

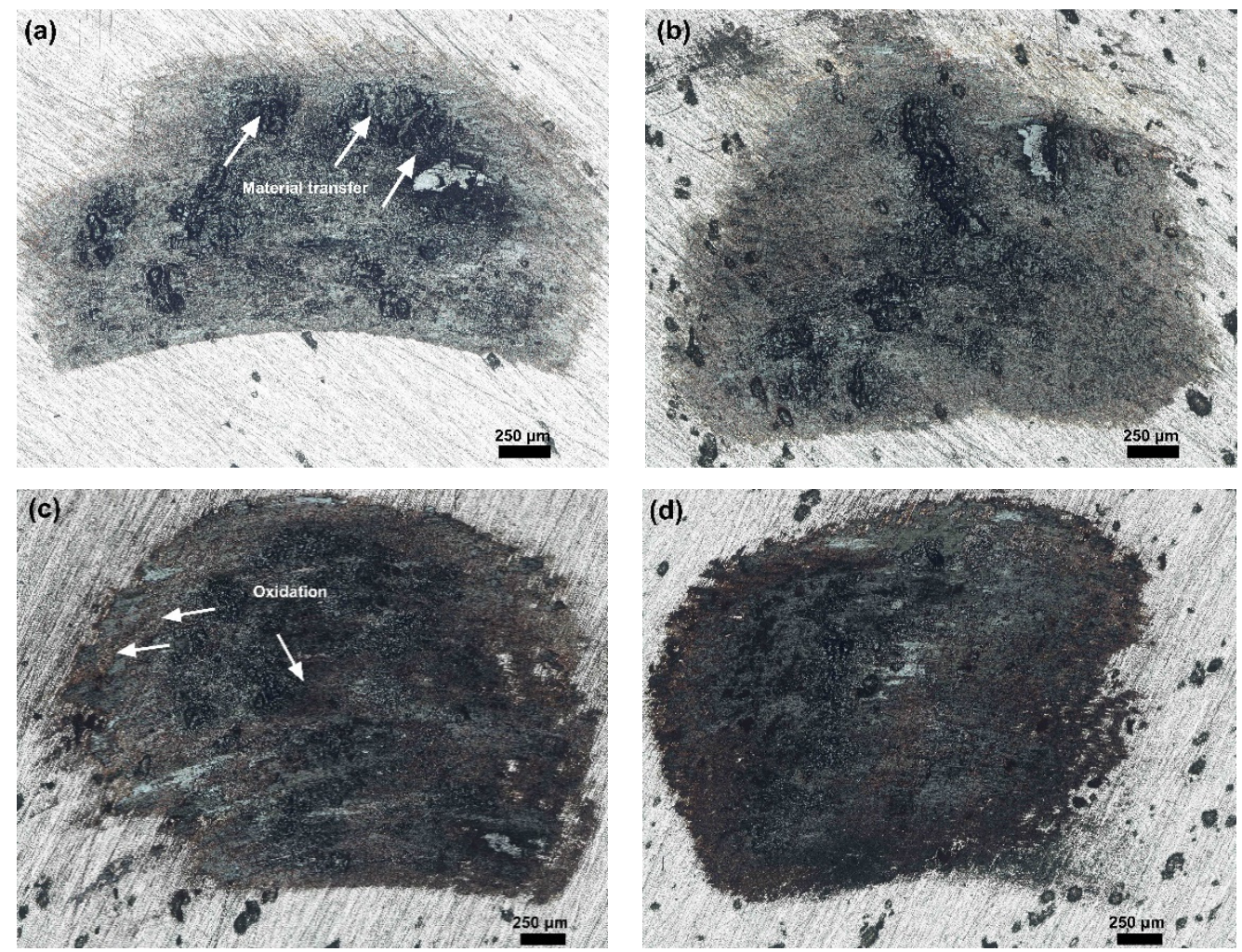

Figure 7. Images of the fretting wear tracks of AM-Inconel 625 at (a) 40; (b) 62; (c) 84 and (d) 106 N.
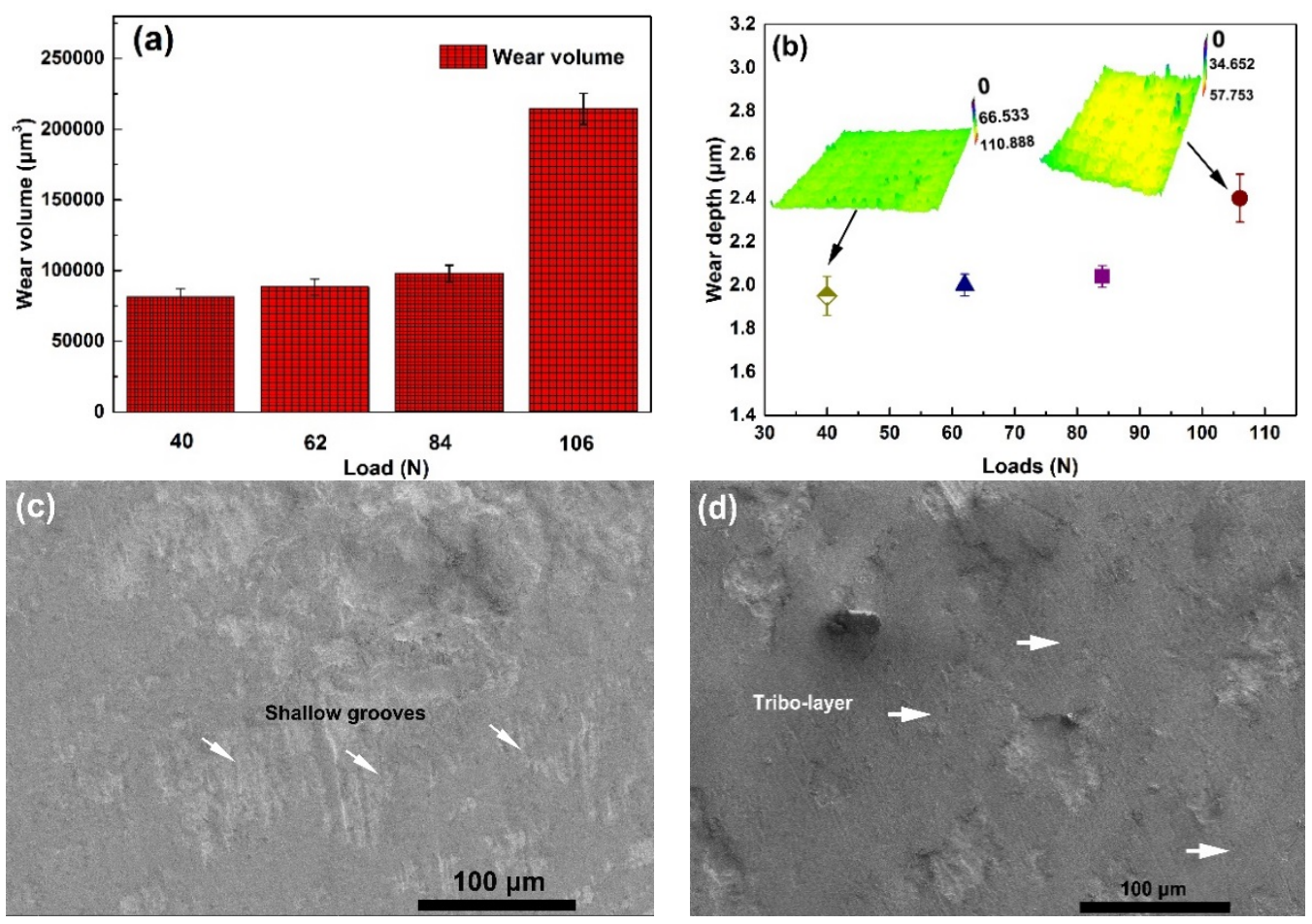

Figure 8. (a) Wear volume and (b) depth of the fretting wear track of AM-Inconel 625 after fretting wear tests; SEM images of the corresponding wear tracks of AM-processed Inconel 625 after tests at (c) 40 and (d) $106 \mathrm{~N}$; the insets in b show 3D surface topographies of the wear track at 40 and $106 \mathrm{~N}$ load, respectively. 
During fretting, the wear volume has been proved to be related to the energy dissipated in the contact. Energy dissipation per cycle of fretting can be obtained by:

$$
E_{f}=2 \int_{0}^{\delta} F_{s} d r=2 F_{s} \delta=2 \mu F_{N} \delta
$$

where $F_{s}=\mu \cdot F_{N}$ is the frictional force, $\mu$ and $F_{N}$ are the friction coefficient and the normal load, respectively, $\delta$ is the displacement amplitude. With the increased normal load, kinetic energy dissipation increases and the thermal effect plays a significant role in the tribo-oxidation. Meanwhile, the abrasion action of wear debris could be aggravated, leading to the increased wear volume. The calculated values of the dissipation energy with increasing normal load are shown in Table 3.

Table 3. Dissipated energy with the increasing normal load.

\begin{tabular}{ccc}
\hline Normal Load (N) & Friction Coefficient & Dissipation Energy (J) \\
\hline $\mathbf{4 0}$ & 0.39 & $47.44 \times 10^{-4}$ \\
$\mathbf{6 2}$ & 0.42 & $62.50 \times 10^{-4}$ \\
$\mathbf{8 4}$ & 0.46 & $92.74 \times 10^{-4}$ \\
$\mathbf{1 0 6}$ & 0.50 & $127.20 \times 10^{-4}$ \\
\hline
\end{tabular}

It can be observed that at the same displacement amplitude, an increase of the normal load leads to the increase of dissipated energy because the dissipated energy is related with both the friction coefficient and the normal load (Equation (6)). This dissipated energy can promote the thermo-mechanical induced transformation of surface layer (such as the transformed layer, plastic flow, delamination) and tribo-oxidation. It was found that the wear volume increased linearly with increasing dissipated energy.

Figure $8 \mathrm{~b}$ presents the wear depth of wear tracks at different loads, where the quantified wear can be more clearly observed. Each test of the wear depth was carried out at the same condition for three times. An increasing trend can be seen and the maximum depth $(\sim 2.4 \mu \mathrm{m})$ is obtained at the load of $106 \mathrm{~N}$ after $2 \times 10^{4}$ cycles. The wear depth of the commonly used nickel-based protective thin coatings, such as NiTi film [56] usually varies as $40-140 \mu \mathrm{m}$ per 200 cycles depending on the operating conditions. Thus, it can be demonstrated that the AM-processed Inconel 625 possess extraordinary anti-wear property, which suppresses wear of the fretting contact surface for as long as $2 \times 10^{4}$ cycles. The 3D surface topographies of the wear track at 40 and $106 \mathrm{~N}$ load are further taken as illustrated in the insets of Figure $8 \mathrm{~b}$. No obvious wear can be observed with the AM-processed Inconel 625 alloy.

Detailed SEM images of the corresponding wear tracks of AM-processed Inconel 625 after tests at 40 and $106 \mathrm{~N}$ are shown in Figure 8c,d, respectively and the underlying wear mechanisms for the formation of various topographical features are proposed to be as follows. The presence of shallow discontinuous grooves and a small number of abrasive fragments attached on the wear track at $40 \mathrm{~N}$ (see Figure 8c) reveals the mild abrasive wear and materials transfer during fretting wear. At a high applied load of $106 \mathrm{~N}$, the wear track of Inconel 625 becomes rather smooth and is found to be covered with an adhesion tribo-layer. In the previous works, microstructural changes and tribochemical reaction are often observed near wear tracks in microcrystalline materials, most commonly in the form of the nanocrystalline tribo-layer [57-66]. Such microstructural refinement can result in a further hardened surface and thus leading to the enhancement of the wear-resistance.

In order to get reliable chemical and structural information from the wear tracks of AM-processed Inconel 625, high-resolution XPS spectra obtained on the tested roller specimens are shown in Figure 9. All the spectra were first calibrated from the $C 1$ s peak at binding energy of $284.4 \mathrm{eV}$ from the NISTXPS database. Additional smoothening was done by the Savitzky-Golay method. The background of the spectra was then subtracted followed by fitting on multiple peaks using the Voigt function. Considering the material transfer from the counterpart (42CrMo4 stainless steel), the $\mathrm{Fe} 2 p$ core level spectrum of the tribo-layer is shown in Figure 9a, which could be deconvoluted into five components. The peak 
at $712.2 \mathrm{eV}$ [67] corresponds to $\mathrm{Fe}_{3} \mathrm{O}_{4}$ which is formed through oxidation during the fretting wear, while the peak at $713.3 \mathrm{eV}$ corresponded to $2 p_{3 / 2}$ of $\mathrm{Fe}^{3+}$ oxidation state [68]. The Fe $2 p_{3 / 2}$ peak at $717.3 \mathrm{eV}$ suggests the existence of $\mathrm{Fe}^{2+}$ and $\mathrm{Fe}^{3+}$ in wear tracks [69]. The peak at $724.0 \mathrm{eV} \mathrm{[66]}$ is identified as $\mathrm{Fe}_{2} \mathrm{O}_{3}$, while $732.5 \mathrm{eV}$ is $\mathrm{Fe}_{3} \mathrm{O}_{4}$ [21]. The existence of both $\mathrm{Fe}_{2} \mathrm{O}_{3}$ and $\mathrm{Fe}_{3} \mathrm{O}_{4}$ in the tribo-layer confirms that the observed material transfer with tribo-oxidation reaction plays an important role in the formation of the tribo-layer. Figure $9 \mathrm{~b}$ shows the $\mathrm{Cr} 2 p$ core level spectra for the wear track of AM-processed Inconel 625. The peak at $576.1 \mathrm{eV}$ [70] is identified as $\mathrm{Cr}_{2} \mathrm{O}_{3}$, while the one at $585.7 \mathrm{eV}$ is identified as $\mathrm{Cr}^{3+} 2 p_{1 / 2}$. The $\mathrm{Mn} 2 p$ spectra of the wear track are shown in Figure 9c. A peak position is obtained at $641.7 \mathrm{eV}$ [71] which corresponds to the oxidation state of $\mathrm{Mn}_{2} \mathrm{O}_{3}$. The aforementioned results demonstrate that the well adhering tribo-layer is mainly composed of mixed oxides. Such layer is normally characterized by a nano-scale structure. Kato and co-workers [72] reported the formation of similar metal oxide nano-particles on the wear track and found that a mild wear regime could be established for those oxides with the higher diffusion coefficients and observed coherent tribo-films. Therefore, the high wear-resistance observed on the AM-processed Inconel 625 shows strong dependence on the good mechanical properties including superior tensile and yield strengths, high hardness, as well as the nature of the tribo-layer formed during fretting wear.
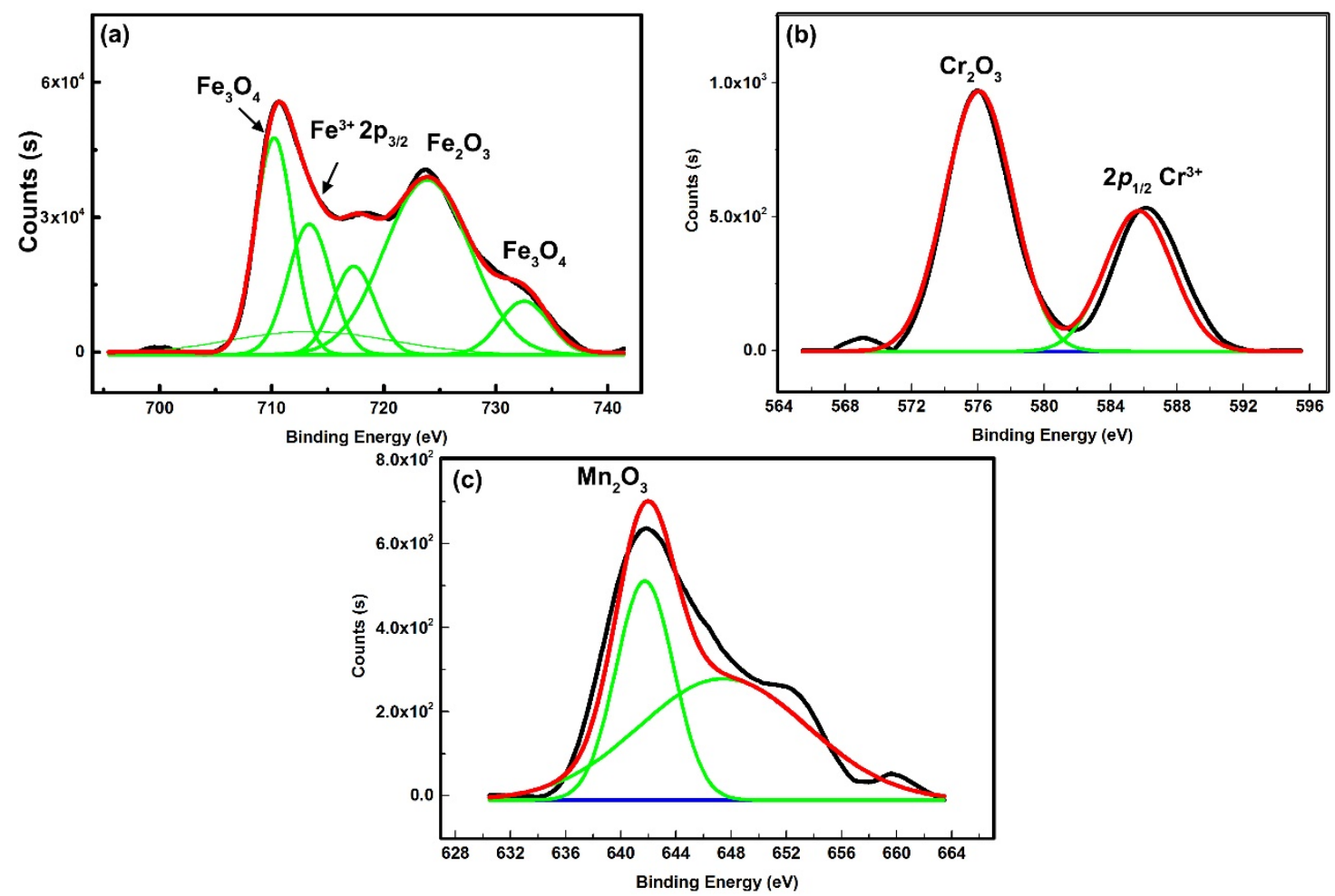

Figure 9. High-resolution XPS spectra obtained on the wear tracks of AM-Inconel 625 after fretting wear.

\section{Conclusions}

This study investigates the micro-hardness, tensile strength, yield strength, friction and wear behaviors of AM-processed Inconel 625 alloy to evaluate the effect of AM processing on the mechanical and tribological performance of nickel-based superalloys. AM-processed Inconel 625 shows the significant improvement in tensile and yield strengths, as well as the wear-resistance compared to traditional nickel-based superalloys under the current test conditions. The results concluded from the experimental investigation are as follows:

- Mechanical test results reveal that the AM-processed Inconel 625 have high hardness value (335 HV), superior tensile strength $(952 \pm 18 \mathrm{MPa})$ and yield strength $(793 \mathrm{MPa})$, as well as excellent wear-resistance. 
- Contributions of precipitates and GB strengthening can be quantitatively calculated for the AM-Inconel 625 alloy. The precipitates and GB contribute 27.9 and $66.7 \mathrm{MPa}$, respectively, to the overall strength.

- The wear depth of traditional nickel-based materials usually varies 40-140 $\mu \mathrm{m}$ per 200 cycles depending on the operating conditions. However, the AM-processed Inconel 625 alloy demonstrates the good wear-resistance, which controls wear depth of the fretting surface within $2.4 \mu \mathrm{m}$ after $2 \times 10^{4}$ cycles.

- The wear characteristics of AM-processed Inconel 625 depend significantly on the continuous tribo-layers. XPS analysis shows that the observed stable and coherent tribo-layer is characterized by a mixture of $\mathrm{Fe}_{2} \mathrm{O}_{3}, \mathrm{Fe}_{3} \mathrm{O}_{4}, \mathrm{Cr}_{2} \mathrm{O}_{3}$ and $\mathrm{Mn}_{2} \mathrm{O}_{3}$.

Author Contributions: Y.G. and M.Z. developed the methodology. Y.G. leads the project. M.Z. prepared samples. Y.G. and M.Z. carried out the experiments. Y.G. and M.Z. analyzed the data. M.Z. wrote the manuscript. Y.G. and M.Z. revised the manuscript.

Funding: This research was funded by [the National Key R\&D Program of China] grant number [2017YFB0103000].

Conflicts of Interest: The authors declare no conflict of interest.

\section{References}

1. Spierings, A.B.; Starr, T.L.; Wegener, K. Fatigue performance of additive manufactured metallic parts. Rapid Prototyp. J. 2013, 19, 88-94. [CrossRef]

2. Chlebus, E.; Kuźnicka, B.; Kurzynowski, T.; Dybała, B. Microstructure and mechanical behaviour of Ti-6Al-7Nb alloy produced by selective laser melting. Mater. Charact. 2011, 62, 488-495. [CrossRef]

3. Wang, F. Mechanical property study on rapid additive layer manufacture Hastelloy ${ }^{\circledR} \mathrm{X}$ alloy by selective laser melting technology. Int. J. Adv. Manuf. Tech. 2012, 58, 545-551. [CrossRef]

4. Paul, C.P.; Ganesh, P.; Mishra, S.K.; Bhargava, P.; Negi, J.; Nath, A.K. Investigating laser rapid manufacturing for Inconel-625 components. Opt. Laser Technol. 2007, 39, 800-805. [CrossRef]

5. Shankar, V.; Rao, K.B.S.; Mannan, S.L. Microstructure and mechanical properties of Inconel 625 superalloy. J. Nucl. Mater. 2001, 288, 222-232. [CrossRef]

6. Yadroitsev, I.; Thivillon, L.; Bertrand, P.; Smurov, I. Strategy of manufacturing components with designed internal structure by selective laser melting of metallic powder. Appl. Surf. Sci. 2007, 254, 980-983. [CrossRef]

7. Li, S.; Wei, Q.S.; Shi, Y.S.; Zhu, Z.C.; Zhang, D.Q. Microstructure Characteristics of Inconel 625 Superalloy Manufactured by Selective Laser Melting. J. Mater. Sci. Technol. 2015, 31, 946-952. [CrossRef]

8. Iwabuchi, A. Fretting wear of inconel 625 at high temperature and in high vacuum. Wear 1985, 106, 163-175. [CrossRef]

9. Hong, C.; Gu, D.; Dai, D.; Alkhayat, M.; Urban, W.; Yuan, P.; Cao, S.; Gasser, A.; Weisheit, A.; Kelbassa, I. Laser additive manufacturing of ultrafine TiC particle reinforced Inconel 625 based composite parts: Tailored microstructures and enhanced performance. Mater. Sci. Eng. A 2015, 635, 118-128. [CrossRef]

10. Lotfi, M.; Jahanbakhsh, M.; Farid, A.A. Wear estimation of ceramic and coated carbide tools in turning of Inconel 625: 3D FE analysis. Tribol. Int. 2016, 99, 107-116. [CrossRef]

11. Sames, W.; List, F.; Pannala, S.; Dehoff, R.; Babu, S. The metallurgy and processing science of metal additive manufacturing. Int. Mater. Rev. 2016, 61, 1-46. [CrossRef]

12. Lewandowski, J.J.; Seifi, M. Metal Additive Manufacturing: A Review of Mechanical Properties. Annu. Rev. Mater. Res. 2016, 46, 151-186. [CrossRef]

13. Basak, A.; Das, S. Epitaxy and Microstructure Evolution in Metal Additive Manufacturing. Annu. Rev. Mater. Res. 2016, 46, 527-530. [CrossRef]

14. Ramsperger, M.; Mújica Roncery, L.; Lopez-Galilea, I.; Singer, R.F.; Theisen, W.; Körner, C. Solution Heat Treatment of the Single Crystal Nickel-Base Superalloy CMSX-4 Fabricated by Selective Electron Beam Melting. Adv. Eng. Mater. 2015, 17, 1486-1493. [CrossRef]

15. Gu, D.; Meiners, W. Microstructure characteristics and formation mechanisms of in situ WC cemented carbide based hardmetals prepared by Selective Laser Melting. Mater. Sci. Eng. A 2010, 527, 7585-7592. [CrossRef] 
16. Calleja, A.; Tabernero, I.; Fernández, A.; Celaya, A.; Lamikiz, A.; López de Lacalle, L.N. Improvement of strategies and parameters for multi-axis laser cladding operations. Opt. Laser Eng. 2014, 56, 113-120. [CrossRef]

17. Martínez Krahmer, D.; Polvorosa, R.; López de Lacalle, L.N.; Alonso-Pinillos, U.; Abate1, G.; Riu, F. Alternatives for Specimen Manufacturing in Tensile Testing of Steel Plates. Exp. Tech. 2016, 40, 1555-1565. [CrossRef]

18. Zhai, W.; Lu, W.; Liu, X.; Zhou, L. Nanodiamond as an effective additive in oil to dramatically reduce friction and wear for fretting steel/copper interfaces. Tribol. Int. 2019, 129, 75-81. [CrossRef]

19. Zhai, W.; Lu, W.; Zhang, P.; Wang, J.; Liu, X.; Zhou, L. Wear-triggered self-healing behavior on the surface of nanocrystalline nickel aluminum bronze/ $\mathrm{Ti}_{3} \mathrm{SiC}_{2}$ composites. Appl. Surf. Sci. 2018, 436, 1038-1049. [CrossRef]

20. Zhai, W.; Lu, W.; Chen, Y.; Liu, X.; Zhou, L.; Lin, D. Gas-atomized copper-based particles encapsulated in graphene oxide for high wear-resistant composites. Compos. Part B 2019, 157, 131-139. [CrossRef]

21. Zhou, M.; Lu, W.; Liu, X.; Zhai, W.; Zhang, P.; Zhang, G. Fretting wear properties of plasma-sprayed $\mathrm{Ti}_{3} \mathrm{SiC}_{2}$ coatings with oxidative crack-healing feature. Tribol. Int. 2018, 118, 196-207. [CrossRef]

22. Mostafaei, A.; Toman, J.; Stevens, E.L.; Hughes, E.T.; Krimer, Y.L.; Chmielus, M. Microstructural evolution and mechanical properties of differently heat-treated binder jet printed samples from gas- and water-atomized alloy 625 powders. Acta Mater. 2016, 122, 280-289. [CrossRef]

23. Tian, Y.; Gontcharov, A.; Gauvin, R.; Lowden, P.; Brochu, M. Effect of heat treatment on microstructure evolution and mechanical properties of Inconel 625 with $0.4 \mathrm{wt} \%$ boron modification fabricated by gas tungsten arc deposition. Mater. Sci. Eng. A 2016, 684, 275-283. [CrossRef]

24. Wang, J.F.; Sun, Q.J.; Wang, H.; Liu, J.P.; Feng, J.C. Effect of location on microstructure and mechanical properties of additive layer manufactured Inconel 625 using gas tungsten arc welding. Mater. Sci. Eng. A 2016, 676, 395-405. [CrossRef]

25. Wang, P.; Li, T.; Lim, Y.F.; Tan, C.K.I.; Chi, D. Sintering and mechanical properties of mechanically milled Inconel 625 superalloy and its composite reinforced by carbon nanotube. Met. Powder Rep. 2016. [CrossRef]

26. Li, G.; Huang, J.; Wu, Y. An investigation on microstructure and properties of dissimilar welded Inconel 625 and SUS 304 using high-power $\mathrm{CO}_{2}$ laser. Int. J. Adv. Manuf. Technol. 2015, 76, 1203-1214. [CrossRef]

27. Jalal, M.; Ramezanianpour, A.A.; Pool, M.K. Split tensile strength of binary blended self compacting concrete containing low volume fly ash and $\mathrm{TiO}_{2}$ nanoparticles. Compos. Part B 2013, 55, 324-337. [CrossRef]

28. Gupta, R.K.; Anil Kumar, V.; Gururaja, U.V.; Shivaram, B.R.N.V.; Maruti Prasad, Y.; Ramkumar, P.; Chakravarthi, K.V.A.; Sarkar, P. Processing and Characterization of Inconel 625 Nickel Base Superalloy. Mater. Sci. Forum 2015, 38, 830-831. [CrossRef]

29. Ma, D.; Stoica, A.D.; Wang, Z.; Beese, A.M. Crystallographic texture in an additively manufactured nickel-base superalloy. Mater. Sci. Eng. A 2017, 684, 47-53. [CrossRef]

30. Ashtiani, H.R.R.; Zarandooz, R. Microstructural and mechanical properties of resistance spot weld of Inconel 625 supper alloy. Int. J. Adv. Manuf. Technol. 2016, 84, 607-619. [CrossRef]

31. Hehr, A.; Dapino, M.J. Interfacial shear strength estimates of NiTi-Al matrix composites fabricated via ultrasonic additive manufacturing. Compos. Part B 2015, 77, 199-208. [CrossRef]

32. Wang, Z.; Palmer, T.A.; Beese, A.M. Effect of processing parameters on microstructure and tensile properties of austenitic stainless steel 304L made by directed energy deposition additive manufacturing. Acta Mater. 2016, 110, 226-235. [CrossRef]

33. Lloyd, D.J. Precipitation Hardening. Metall. Mater. Trans. A 1985, 16, 2131-2165.

34. Courtney, T.H. Mechanical Behavior of Materials; Waveland Press: Long Grove, IL, USA, 2005.

35. Crudden, D.J.; Mottura, A.; Warnken, N.; Raeisinia, B.; Reed, R.C. Modelling of the influence of alloy composition on flow stress in high-strength nickel-based superalloys. Acta Mater. 2014, 75, 356-370. [CrossRef]

36. Thompson, A.A. Yielding in nickel as a function of grain or cell size. Acta Metall. 1975, 23, 1337-1342. [CrossRef]

37. Chen, X.H.; Lu, L.; Lu, K. Grain size dependence of tensile properties in ultrafine-grained Cu with nanoscale twins. Scr. Mater. 2011, 64, 311-314. [CrossRef] 
38. Ma, K.; Wen, H.; Hu, T.; Topping, T.D.; Isheim, D.; Seidman, D.N.; Lavernia, E.J.; Schoenung, J.M. Mechanical behavior and strengthening mechanisms in ultrafine grain precipitation-strengthened aluminum alloy. Acta Mater. 2014, 62, 141-155. [CrossRef]

39. Basu, B.; Vitchev, R.G.; Vleugels, J.; Celis, J.P.; Biest, O.V.D. Influence of humidity on the fretting wear of self-mated tetragonal zirconia ceramics. Acta Mater. 2000, 48, 2461-2471. [CrossRef]

40. Wang, J.; Luo, X.H.; Sun, Y.H. Torsional Fretting Wear Properties of Thermal Oxidation-Treated $\mathrm{Ti}_{3} \mathrm{SiC}_{2}$ Coatings. Coatings 2018, 8, 324. [CrossRef]

41. Tewari, A.; Basu, B.; Bordia, R.K. Model for fretting wear of brittle ceramics. Acta Mater. 2009, 57, $2080-2087$. [CrossRef]

42. Swaminathan, V.; Gilbert, J.L. Fretting corrosion of CoCrMo and $\mathrm{Ti}_{6} \mathrm{Al}_{4} \mathrm{~V}$ interfaces. Biomaterials 2012, 33, 5487-5503. [CrossRef] [PubMed]

43. Sikdar, K.; Shekhar, S.; Balani, K. Fretting wear of Mg-Li-Al based alloys. Wear 2014, 318, 177-187. [CrossRef]

44. Lan, P.; Meyer, J.L.; Vaezian, B.; Polycarpou, A.A. Advanced polymeric coatings for tilting pad bearings with application in the oil and gas industry. Wear 2016, 354, 10-20. [CrossRef]

45. Zhang, P.; Liu, X.; Lu, W.; Zhai, W.; Zhou, M.; Wang, J. Fretting wear behavior of CuNiAl against 42CrMo4 under different lubrication conditions. Tribol. Int. 2018, 117, 59-67. [CrossRef]

46. Zhang, P.; Lu, W.; Liu, X.; Zhai, W.; Zhou, M.; Jiang, X. A comparative study on torsional fretting and torsional sliding wear of CuNiAl under different lubricated conditions. Tribol. Int. 2018, 117, 78-86. [CrossRef]

47. Zhang, P.; Lu, W.; Liu, X.; Zhai, W.; Zhou, M.; Zeng, W. Torsional fretting and torsional sliding wear behaviors of $\mathrm{CuNiAl}$ against $42 \mathrm{CrMo}_{4}$ under dry condition. Tribol. Int. 2018, 118, 11-19. [CrossRef]

48. Lu, W.; Zhai, W.; Zhang, P.; Zhou, M.; Liu, X.; Zhou, L. Effect of different levels of free water in oil on the fretting wear of nickel-aluminum bronze based composites. Wear 2017, 390-391, 376-384. [CrossRef]

49. Zhai, W.; Lu, W.; Zhang, P.; Zhou, M.; Liu, X.; Zhou, L. Microstructure, mechanical and tribological properties of nickel-aluminium bronze alloys developed via gas-atomization and spark plasma sintering. Mater. Sci. Eng. A 2017, 707, 325-336. [CrossRef]

50. Zhang, P.; Lu, W.; Liu, X.; Zhou, M.; Zhai, W.; Zhang, G.; Zeng, W.; Jiang, X. Torsional fretting wear behavior of $\mathrm{CuNiAl}$ against $42 \mathrm{CrMo} 4$ under flat on flat contact. Wear 2017, 380, 6-14. [CrossRef]

51. Zhang, P.; Lu, W.; Liu, X.; Zhou, M.; Zhai, W.; Zhang, G.; Zeng, W.; Jiang, X.; Lu, W.; Zhang, P.; et al. Influence of surface topography on torsional fretting wear under flat-on-flat contact. Tribol. Int. 2017, 109, 367-372.

52. Zhai, W.; Shi, X.; Yang, K.; Huang, Y.; Zhou, L.; Lu, W. Mechanical and tribological behaviors of the tribo-layer of the nanocrystalline sturcture during sliding contact: Experiments and model assessment. Compos. Part $B$ 2017, 108, 354-363. [CrossRef]

53. Zhai, W.; Shi, X.; Yang, K.; Zhou, L.; Lu, W. Tribological Behaviors of $\mathrm{Ni}_{3} \mathrm{Al}$ Intermetallics with $\mathrm{MoO}_{3}$ Multilayer Ribbon Crystal Prepared by Spark Plasma Sintering. Acta Metall. Sin Engl. 2017, 30, 576-584. [CrossRef]

54. Lu, W.; Zhang, G.; Liu, X.; Jiang, X. Prediction of surface topography at the end of sliding running-in wear based on areal surface parameters. Tribol. Trans. 2014, 57, 553-560. [CrossRef]

55. Yang, K.; Ma, H.; Li, X.; He, Q. The Analysis in In Situ Preparation, Mechanics and Tribology of TiAl-SnAgCu/Graphene Composites. Adv. Eng. Mater. 2018, 800719, 1-8. [CrossRef]

56. Ng, K.L.; Sun, Q.P.; Tomozawa, M.; Miyazak, S. Wear behavior of NITI thin film at micro-scale. Int. J. Mod. Phys. B 2012, 24, 85-93. [CrossRef]

57. Shi, W.; Luo, X.; Zhang, Z.; Liu, Y.; Lu, W. Influence of external load on the frictional characteristics of rotary model using a molecular dynamics approach. Comput. Mater. Sci. 2016, 122, 201-209. [CrossRef]

58. Lan, P.; Zhang, Y.; Dai, W.; Polycarpou, A. A phenomenological elevated temperature friction model for viscoelastic polymer coatings based on nanoindentation. Tribol. Int. 2018, 119, 299-307. [CrossRef]

59. Lan, P.; Polychronopoulou, K.; Zhang, Y.; Polycarpou, A.A. Three-body abrasive wear by (silica) sand of advanced polymeric coatings for tilting pad bearings. Wear 2017, 382, 40-50. [CrossRef]

60. Lan, P.; Gheisari, R.; Meyer, J.; Polycarpou, A. Tribological performance of aromatic thermosetting polyester (ATSP) coatings under cryogenic conditions. Wear 2018, 398, 47-55. [CrossRef]

61. Lan, P.; Meyer, J.L.; Economy, J.; Polycarpou, A.A. Unlubricated tribological performance of aromatic thermosetting polyester (ATSP) coatings under different temperature conditions. Tribol. Lett. 2016, 61, 10.

62. Zhang, G.; Liu, X.; Lu, W. A parameter prediction model of running-in based on surface topography. Proc. Inst. Mech. Eng. Part C 2013, 227, 1047-1055. [CrossRef] 
63. Zhang, H.; Brown, L.; Blunt, L.; Jiang, X.; Barrans, S. The contribution of the micropores in bone cement surface to generation of femoral stem wear in total hip replacement. Tribol. Int. 2011, 44, 1476-1482. [CrossRef]

64. Zhang, H.; Brown, L.T.; Blunt, L.A.; Jiang, X.; Barrans, S.M. Understanding initiation and propagation of fretting wear on the femoral stem in total hip replacement. Wear 2009, 266, 566-569. [CrossRef]

65. Lan, P.; Polycarpou, A. High temperature and high pressure tribological experiments of advanced polymeric coatings in the presence of drilling mud for oil \& gas applications. Tribol. Int. 2018, 120, $218-225$.

66. Shakoor, R.A.; Waware, U.S.; Ali, K.; Kahraman, R.; Popelka, A.; Yusuf, M.M.; Hasan, A. Novel Electrodeposited Ni-B/Y2O3 Composite Coatings with Improved Properties. Coatings 2017, 7, 161. [CrossRef]

67. Tan, B.J.; Klabunde, K.J.; Sherwood, P.M.A. X-ray photoelectron spectroscopy studies of solvated metal atom dispersed catalysts. Monometallic iron and bimetallic iron-cobalt particles on alumina. Chem. Mater. 2002, 2, 186-191. [CrossRef]

68. Brion, D. Etude par spectroscopie de photoelectrons de la degradation superficielle de $\mathrm{FeS}_{2}, \mathrm{CuFeS}_{2}, \mathrm{ZnS}$ et PbS a l'air et dans l'eau. Appl. Surf. Sci. 1980, 5, 133-152. [CrossRef]

69. Kar, P.K.; Singh, G. Evaluation of Nitrilotrimethylene Phosphonic Acid and Nitrilotriacetic Acid as Corrosion Inhibitors of Mild Steel in Sea Water. ISRN Mater. Sci. 2011, 2011, 167487. [CrossRef]

70. Grohmann, I.; Kemnitz, E.; Lippitz, A.; Unger, W.E.S. Curve fitting of Cr 2p photoelectron spectra of $\mathrm{Cr}_{2} \mathrm{O}_{3}$ and $\mathrm{CrF}_{3}$. Surf. Int. Anal. 2004, 23, 887-891. [CrossRef]

71. Allen, G.C.; Harris, S.J.; Jutson, J.A.; Dyke, J.M. A study of a number of mixed transition metal oxide spinels using X-ray photoelectron spectroscopy. Appl. Surf. Sci. 1989, 37, 111-134. [CrossRef]

72. Kato, H.; Komai, K. Tribofilm formation and mild wear by tribo-sintering of nanometer-sized oxide particles on rubbing steel surfaces. Wear 2007, 262, 36-41. [CrossRef]

(C) 2018 by the authors. Licensee MDPI, Basel, Switzerland. This article is an open access article distributed under the terms and conditions of the Creative Commons Attribution (CC BY) license (http://creativecommons.org/licenses/by/4.0/). 